\title{
Predictors of continued HIV-risk behaviors among drug users in methadone maintenance therapy program in China-A prospective study
}

Wen Chen ${ }^{1,2}$, Yinghua Xia ${ }^{1,2}$, Yan Hong ${ }^{3}$, Brian J Hall ${ }^{2,4,5}$ and Li Ling ${ }^{1,2^{*}}$

\begin{abstract}
Background: To examine the predictors of continued drug- and sex-related HIV-risk behaviors among drug users in methadone maintenance therapy (MMT) programs in China.

Methods: We followed a sample of 5,035 drug users enrolled for the first time in MMT programs at baseline, 6 months, and 12 months utilizing a longitudinal prospective study design. Drug users' HIV-risk behaviors, MMT characteristics, and drug use, were assessed at all three waves using a structured interview and HIV/HCV status was assessed at baseline and 12-month follow-up using biological specimens.

Results: The point prevalence of HIV was $7.6 \%$ and $78.4 \%$ for HCV at baseline. Results of generalized linear mixed logistic regression models revealed that HIV-positive MMT clients were more likely to engage in drug injection $(\mathrm{aOR}=1.70)$ and syringe sharing $(\mathrm{aOR}=4.73) . \mathrm{HCV}$-positive clients were more likely to inject drugs $(\mathrm{aOR}=2.58)$, share syringes $(\mathrm{aOR}=1.97)$, and have multiple sexual partners $(\mathrm{aOR}=1.47)$. Adherence to MMT was the most significant predictor of reduced HIV-risk behaviors.

Conclusions: Our data confirmed the positive effects of MMT on HIV prevention and underscored the urgency for programs to reduce HIV risk in HIV- and HCV-positive clients. There is a pressing need to strengthen existing counseling services for HIV-positive drug users to reduce their drug-related risk behaviors and to provide counseling for HCV-positive drug users. Further studies are needed to explore interventions to address high dropout rates and low adherence among MMT clients.
\end{abstract}

Keywords: Methadone maintenance therapy, HIV-risk behaviors, Longitudinal study, China

\section{Background}

Globally, around 36 million people are addicted to heroin and opium, and many of them are HIV positive or at high risk of becoming infected and transmitting the virus to others [1]. Methadone maintenance therapy (MMT) is one of the most popular opioid replacement therapies designed to treat opioid dependence with more than one million people in MMT worldwide [2]. Despite the controversy surrounding MMT [3,4], existing literature has documented the effectiveness of MMT in reducing the risks of drug overdose, drug injection, and transmission

\footnotetext{
* Correspondence: lingli@mail.sysu.edu.cn

${ }^{1}$ Faculty of Medical Statistics and Epidemiology, School of Public Health, Sun Yat-sen University, \#74, Zhongshan Road II, Guangzhou 510080, P.R China ${ }^{2}$ Sun Yat-sen Center for Migrant Health Policy, \#74, Zhongshan Road II, Guangzhou 510080, P.R China

Full list of author information is available at the end of the article
}

of HIV and other blood- borne diseases [5-11]. Most of these studies were conducted in Western countries; limited data exist from developing countries like China, where more than 1.5 million drug users were recently introduced to MMT [12].

Illicit drug use reemerged in China in the early 1980s, when China adapted an open-door policy towards the West [13]. The rates of drug users continued to climb during the next decade and expanded rapidly from 70,000 in 1990 to 1.5 million in 2011 [12,13]. The Chinese government employed the same "eradication" policies instituted in the 1950s in response to the growing drugabuse epidemic. Drug use was portrayed in the media as one of the four "social evils" subject to "fierce crack-down." Periodic "strike-hard" campaigns were organized that targeted individuals engaging in drug use. Identified drug 
users were arrested and sent to detention centers for forced abstinence treatment or "reeducation through labor camps" [14]. Such policies failed to reduce the number of drug users but instead pushed them further underground. Concurrently, the first HIV epidemic broke out among injection drug users (IDU) in Yunnan in 1989 [13,15]. As of 2010, 28.6\% of HIV infections in China were attributed to IDU [16].

In response to the growing HIV epidemic, the Chinese government adopted a more pragmatic approach toward drug abuse. In 2004, MMT was piloted in eight cities; MMT was scaled up nationwide since 2006 [17]. By September 2011, a total of 716 clinics across the country were approved to provide MMT and since that time, more than 332,996 drug users have been enrolled in the program [16]. The MMT system in China has thus become the largest single drug-treatment system in the world [18].

According to the national guidelines of MMT, participation in government-sponsored MMT is voluntary, and each client is required to pay 10 yuan (about \$1.50) per day for the treatment. At enrollment, clients receive comprehensive medical examinations, which include testing for HIV, HCV, TB, syphilis, and liver and kidney diseases. Clients with TB and liver diseases are then referred to appropriate clinics for treatment. These examinations are performed annually during the course of MMT. If clients test positive for HIV, they are referred to the local CDC for antiretroviral treatment (ART). In addition, clients are required to take monthly urine tests for illicit drug use. Clients need to visit an MMT clinic every day. Clinicians provide them with an appropriate dose of methadone based on their individual needs. Clinicians also provide HIV prevention counseling services. A client who fails to return to a MMT clinic for 7 consecutive days is considered to have dropped out of MMT [19]. A high dropout rate has been observed in most MMT clinics in China [20-23]. The most typical reason for dropping out is detention by police or incarceration in detoxification centers. Other leading causes include trying to quit opiate use without MMT, and conflicts with job schedules [22,24].

Existing studies on MMT in China revealed that HIVseropositive rates among IDU who participated in MMT were between $11 \%$ to $29 \%[10,25,26]$. Studies indicate that most MMT clients continue to engage in HIV-risk behaviors while enrolled in MMT programs [10,27]. Therefore, identifying the risk factors associated with continued HIV risks is a public health priority. Available data on these risk factors come primarily from cross-sectional studies with small sample sizes [27-30]. The current study overcomes these limitations by utilizing a longitudinal prospective study design with a large sample of MMT clients. The aims of this investigation were to assess the changes in drug- and sex-related risk behaviors among MMT clients and identify the predictors of continued HIV risks.

\section{Methods \\ Study site}

Our study was conducted in Guangdong Province on the southern coast of China. Guangdong is the frontier of China's economic reform and forerunner in terms of HIV/AIDS epidemic; the total number of HIV-infected individuals was 37, 723 in 2012 October [31] and 26.6\% of HIV infections in Guangdong were transmitted through sharing injection equipment [32]. We employed a twostage stratified sampling methodology by first choosing nine cities in Guangdong Province with different levels of economic development, and then randomly selecting one or two MMT clinics from each participating city. A total of $12 \mathrm{MMT}$ clinics were selected as data collection sites for the current study representing a diverse group of 300,000 drug users [33].

\section{Participants}

Clients were eligible to participate in our study if they met the following criteria: (a) current opioid or heroin dependence according to the International Classification of Diseases-10 (ICD-10) [34], (b) age 20 or older, (c) residence in the area/city where the MMT clinic was located (according to current Chinese policies, only residents with local household registration are eligible for local MMT services), (d) willingness to participate and provide informed consent, and (e) enrollment in the participating MMT program for the first time (to reduce the potential contamination from other HIVprevention or drug treatment programs). At the time of the study, no other HIV prevention programs were offered in the 12 participating MMT clinics. A total of 5,624 new voluntary MMT clients meeting our criteria were enrolled in our stud. Among these participants, 319 were not tested for HIV and were excluded from the data analysis. The final sample included 5,305 participants who were followed over one year. The first follow-up at 6 months had a sample size of 3,123 (58.9\%), and the second follow-up at 12 months had sample size of 2,061 (38.9\%).

\section{Data collection}

Data collection began in January 2006 and concluded in October 2010. At enrollment in the study, participants completed an informed consent and were interviewed by an experienced clinician in a private space at the MMT clinic using a structured interview questionnaire. The questionnaire consisted of demographic information and HIV-related risk behaviors designed by the National 
Working Group on Community-based Methadone Maintenance Treatment for Opium Dependents in China, and was widely used in MMT related studies in China $[35,36]$. Participants completed the same survey about their HIV- and drug-related behaviors at each follow-up and provided blood samples for HIV and HCV testing at baseline and 12-month follow-up as a part of the MMT protocol. Study participation was voluntary, and no participant received any payment or gifts for participating. The study protocol was approved by the Institutional Review Board [37] at the Sun Yat-sen University School of Public Health.

\section{Measurement}

\section{Demographic characteristics}

Were collected during the baseline survey, including age, gender, education, employment status, marital status, and history of drug abuse.

\section{MMT characteristics}

The MMT clinicians recorded clients' daily methadone dosage and other medical information. Client attendance was tracked and the criterion of MMT dropout (and from this current study) was missing 7 consecutive days of MMT. In addition, clients provided monthly urine samples to test for illicit drug use. From these data, we identified three treatment characteristics of the participants; first, mean dosage of methadone, the average amount of methadone the client had taken; second, treatment adherence, the number of days the client adhered to the treatment guidelines and took daily dosage of methadone as required; and third, longest duration of abstinence ( $L D A)$, defined as the longest duration of negative urine tests for drug use.

\section{HIV-risk behaviors}

Drug-related risk behaviors were assessed by inquiring if the participant had injected drugs and whether he or she

Table 1 Demographic and MMT characteristics of MMT clients during the course of treatment

\begin{tabular}{|c|c|c|c|}
\hline Characteristics & $\begin{array}{l}\text { Baseline } \\
(n=5305)\end{array}$ & $\begin{array}{l}\text { 6-month follow-up } \\
(n=3123)\end{array}$ & $\begin{array}{l}\text { 12-month follow-up } \\
(n=2061)\end{array}$ \\
\hline Age (years), mean (SD) & $38.65(6.17)$ & $38.63(6.15)$ & $38.85(6.24)$ \\
\hline \multicolumn{4}{|l|}{$\operatorname{Sex} n(\%)$} \\
\hline Male & $4916(92.67)$ & 2865(91.74) & 1898(92.09) \\
\hline Female & $389(7.33)$ & 258(8.26) & 163(7.91) \\
\hline \multicolumn{4}{|l|}{ Employment status n (\%) } \\
\hline Employed & $3066(57.79)$ & 1928(61.74) & $1287(62.45)$ \\
\hline Unemployed & $2239(42.21)$ & 1195(38.26) & $774(37.55)$ \\
\hline \multicolumn{4}{|l|}{ Marriage status $n(\%)$} \\
\hline Married & 2449(46.16) & $1445(46.26)$ & $968(46.97)$ \\
\hline Unmarried & $2856(53.84)$ & 1698(53.74) & 1093(53.03) \\
\hline \multicolumn{4}{|l|}{ Education $n(\%)$} \\
\hline Primary school & 1038(19.57) & $611(19.56)$ & 406(19.70) \\
\hline Junior school & $3335(62.87)$ & 1923(61.58) & $1241(60.21)$ \\
\hline Senior school or higher & $932(17.57)$ & $589(18.86)$ & 414(20.19) \\
\hline \multicolumn{4}{|l|}{ HIV n (\%) } \\
\hline Positive & $401(7.56)$ & $206(6.60)$ & 148(7.18) \\
\hline Negative & 4904(92.44) & 2917(93.40) & 1913(92.82) \\
\hline \multicolumn{4}{|l|}{ HCV n (\%) } \\
\hline Positive & 3909(78.38) & 2427(79.73) & 1626(80.34) \\
\hline Negative & $1078(21.62)$ & $617(20.27)$ & 398(19.66) \\
\hline Years of drug use before MMT mean (SD) & $15.02(5.04)$ & $15.22(5.06)$ & $15.45(4.88)$ \\
\hline Methadone dosage (mg/day) & - & $51.11(22.05)$ & $52.38(22.17)$ \\
\hline \multicolumn{4}{|l|}{ mean (SD) } \\
\hline Treatment adherence (days) & - & 183.00 & 267.00 \\
\hline mean (SD) & & $(95.00 \sim 183.00)$ & $(152.00 \sim 336.00)$ \\
\hline Longest duration of abstinence (months) median (IQR) & - & $4.00(2.00 \sim 6.00)$ & $4.00(2.00 \sim 7.00)$ \\
\hline
\end{tabular}


had shared syringes in the past one month. Sex-related risk behaviors included whether the participant had unprotected sex in the previous sexual intercourse or whether he or she had multiple sexual partners (more than one) in the past 3 months.

\section{HIV- and HCV-positive status}

MMT clients provided blood samples for HIV and $\mathrm{HCV}$ serum antibody testing at enrollment and 12-month follow-up in the MMT program. Samples were first screened by latex chromatographic, positive samples were further confirmed using the immunoblotting method by the local Centers of Disease Control. Meanwhile, blood samples from each client were tested for hepatitis $\mathrm{C}$ antibody by enzyme-linked immunosorbent assay (ELISA). Pre- and posttest counseling services were provided. National guidelines were followed in all counseling and testing services.

\section{Data analysis}

First, we used $t$-test or Fisher's exact test to compare the key demographics, MMT characteristics, and HIV- and $\mathrm{HCV}$-infection status across the samples at baseline, first follow-up, and second follow-up as well as between the retained sample and dropout sample. Second, we identified the time trend of both drug- and sex-related HIV-risk behaviors during the course of treatment. To best utilize available data and to account for intra-class correlation (ICC) resulting from repeated measures, we used generalized linear mixed models (GLMM) for binary outcomes with a logit link function. Finally, we used logistic regression with GLMM to estimate unadjusted and adjusted odds ratio (aOR) and 95\% confidence

Table 2 Demographic and MMT characteristics between retained and dropout clients at 6- and 12- month follow-up

\begin{tabular}{|c|c|c|c|c|}
\hline \multirow[t]{2}{*}{ Characteristic } & \multicolumn{2}{|c|}{ 6-month follow-up } & \multicolumn{2}{|c|}{ 12-month follow-up } \\
\hline & $\begin{array}{l}\text { Retained } \\
(n=3123)\end{array}$ & $\begin{array}{l}\text { Dropped out } \\
(n=2182)\end{array}$ & $\begin{array}{l}\text { Retained } \\
(n=2061)\end{array}$ & $\begin{array}{l}\text { Dropped out } \\
(n=3244)\end{array}$ \\
\hline Age (yrs) mean (SD) & $38.63(6.15)$ & $38.23(6.10)^{* *}$ & $38.85(6.24)$ & $38.27(6.07)^{* *}$ \\
\hline \multicolumn{5}{|l|}{$\operatorname{Sex} n(\%)$} \\
\hline Male & $2865(91.74)$ & $2071(94.91)^{* * *}$ & $1898(92.09)$ & $3038(93.65)^{* *}$ \\
\hline Female & $258(8.26)$ & $111(5.09)$ & $163(7.91)$ & $206(6.35)$ \\
\hline \multicolumn{5}{|l|}{ Employment $n(\%)$} \\
\hline Employed & $1928(61.74)$ & $1118(51.24)^{* * *}$ & $1287(62.45)$ & $1759(54.22)^{* * *}$ \\
\hline Unemployed & $1195(38.26)$ & $1064(48.76)$ & 774 (37.55) & $1485(45.78)$ \\
\hline \multicolumn{5}{|l|}{ Marital status n (\%) } \\
\hline Married & $1445(46.26)$ & $1004(46.01)$ & $968(46.97)$ & $1481(45.65)^{*}$ \\
\hline Unmarried & $1698(53.74)$ & 1178(53.99) & $1093(53.03)$ & 1763(54.96) \\
\hline \multicolumn{5}{|l|}{ Education $n(\%)$} \\
\hline Primary school & $611(19.56)$ & $427(19.57)^{*}$ & 406(19.70) & $632(19.48)^{* * *}$ \\
\hline Junior school & 1923(61.58) & 1412(64.71) & $1241(60.21)$ & $2094(64.55)$ \\
\hline Senior school or higher & $589(18.86)$ & $343(15.72)$ & $414(20.19)$ & $518(15.97)$ \\
\hline \multicolumn{5}{|l|}{ HIV n (\%) } \\
\hline Positive & $206(6.60)$ & $195(8.94)^{* *}$ & 148(7.18) & 253(7.80) \\
\hline Negative & 2917(93.40) & 1987(91.06) & 1913(92.82) & 2991(92.20) \\
\hline \multicolumn{5}{|l|}{$\mathrm{HCV} n(\%)$} \\
\hline Positive & $2427(79.73)$ & $1482(76.27)^{* *}$ & $1626(80.34)$ & $2283(77.05)^{* *}$ \\
\hline Negative & $617(20.27)$ & $461(23.73)$ & 398(19.66) & $680(22.95)$ \\
\hline Yrs of drug use before MMT & $15.22(5.06)$ & $14.74(5.00)^{* *}$ & 15.45(4.88) & $14.75(5.12)^{* * *}$ \\
\hline \multicolumn{5}{|l|}{ mean (SD) } \\
\hline Methadone dosage (mg/day) mean (SD) & $51.11(22.05)$ & $44.10(18.94)^{* * *}$ & $52.38(22.17)$ & $45.59(19.98)^{* * *}$ \\
\hline \multirow[t]{2}{*}{ Treatment adherence (days), mean (SD) } & 183.00 & 36.00 & 267.00 & 53.00 \\
\hline & $(95.00 \sim 183.00)$ & $(14.00 \sim 90.00)^{* * *}$ & $(152.00 \sim 336.00)$ & $(18.00 \sim 143.00)^{* * *}$ \\
\hline Longest duration of abstinence (months) median (IQR) & $4.00(2.00 \sim 6.00)$ & $0.00(0.00 \sim 1.00)^{* * *}$ & $4.00(2.00 \sim 7.00)$ & $1.00(0.00 \sim 2.75)^{* * *}$ \\
\hline
\end{tabular}

${ }^{*} p<0.05,{ }^{* *} p<0.01,{ }^{* * *} p<0.001$. 
intervals (CI) for the predictors of continued HIV-risk behaviors. Four bivariate models (to produce the "unadjusted OR" for four types of HIV risk behaviors) and four multivariable models (to produce the "adjusted OR" for four types of HIV risk behaviors) were conducted on outcomes obtained at 12-month follow-up. Variance components, with the VC command, was chosen as covariance structure for the repeated measures, based on Akaike's information criteria (AIC) [38]. All statistical analyses were performed using SAS 9.3 and the SAS procedure PROC GLIMMIX (SAS Institute Inc., Cary, NC, USA).

\section{Results}

Demographic and MMT characteristics over 12 months of follow-up

As depicted in Table 1, at the baseline, the mean age of MMT participants was 38.6 years $(\mathrm{SD}=6.17)$, and the mean length of drug use prior to MMT was 15 years $(\mathrm{SD}=5)$. Most participants were male $(93 \%), 46 \%$ were married, 58\% were employed, and 18\% had completed secondary school. Approximately $7.6 \%$ were HIV positive and $78.4 \%$ were $\mathrm{HCV}$ positive. Participants in the first follow-up had a mean 183 treatment-adherence days and a median 4 months of abstinence. Participants in the second follow-up had a mean 267 treatment-adherence days and a median 4 months of abstinence. As shown in Table 2, the retained participants and dropouts differed significantly in most key demographic and MMT characteristics. Dropouts were more likely to be younger, male, less educated, HIV-positive, HCV-positive, with a shorter drug use history, a lower dosage of methadone, and a shorter duration of abstinence.

\section{Changes of HIV risk behaviors at three measurements}

As shown in Table 3, drug-related HIV-risk behaviors decreased throughout the course of treatment. Injecting drugs in the past month decreased from $82 \%$ at baseline to $30 \%$ at first follow-up and $22.5 \%$ at second follow-up. Sharing needles decreased from $18.6 \%$ to $4.9 \%$ to $4.0 \%$. Sex-related risk behaviors had mixed responses to the treatment. For instance, having unprotected sex in the last sexual intercourse decreased from $56.9 \%$ to $54.1 \%$ at first follow-up and remained at the same level at second follow-up. Having multiple sexual partners in the past 3 months decreased from $9.4 \%$ at baseline to $6.8 \%$ at first follow-up but increased to $9.3 \%$ at second follow-up.

\section{Predictors of continued HIV-risk behaviors}

Tables 4 and 5 present the predictors of drug- and sexrelated risk behaviors. In the multivariable model, after controlling for potential confounders and ICC, the following variables significantly increased the risk of drug injection: younger age, longer history of drug use, being male, unemployment, not completing secondary school, being unmarried, HIV positive, HCV positive, lower mean dosage of methadone, lower level of treatment adherence and shorter duration of abstinence.

The following variables significantly increased the risk of sharing needles: younger age, longer history of drug use, being HIV or HCV positive, lower level of treatment adherence, shorter duration of abstinence, having unprotected sex prior to MMT and having multiple sexual partners prior to MMT.

The significant predictors for unprotected sex included younger age, longer history of drug use, unemployment, being married, being HIV or HCV positive, lower mean

Table 3 Changes in HIV risk behaviors during the course of MMT treatment

\begin{tabular}{|c|c|c|c|}
\hline Risk behaviors & $\begin{array}{l}\text { Baseline } \\
(n=5305)\end{array}$ & $\begin{array}{l}\text { 6-month follow-up } \\
(n=3123)\end{array}$ & $\begin{array}{l}\text { 12-month follow-up } \\
(n=2061)\end{array}$ \\
\hline \multicolumn{4}{|c|}{ Drug injection in the past 1 month } \\
\hline Yes & $4368(82.34)$ & $937(30.00)$ & $464(22.51)^{* * *}$ \\
\hline No & $937(17.66)$ & 2186(70.00) & 1597(77.49) \\
\hline \multicolumn{4}{|c|}{ Syringe sharing in the past 1 month } \\
\hline Yes & $988(18.62)$ & $154(4.93)$ & $83(4.03)^{* * *}$ \\
\hline No & $4317(81.38)$ & 2969(95.07) & 1978(95.97) \\
\hline \multicolumn{4}{|c|}{ Unprotected sex at last sexual encounter } \\
\hline Yes & $1782(56.88)$ & 1078(54.09) & $695(54.64)^{*}$ \\
\hline No & $1351(43.12)$ & $915(45.91)$ & $577(45.36)$ \\
\hline \multicolumn{4}{|c|}{ Multiple sexual partners in the past 3 months } \\
\hline Yes & $401(9.35)$ & 213(6.83) & $118(9.30)^{* * *}$ \\
\hline No & $3887(90.65)$ & 2905(93.17) & $1151(90.70)$ \\
\hline
\end{tabular}

Main effect of time: ${ }^{*} p<0.05,{ }^{* * *} p<0.001$. 
Table 4 Generalized linear mixed models (GLMM) logistic regression results: Predictors of continued drug-related risk behaviors

\begin{tabular}{|c|c|c|c|c|}
\hline \multirow[t]{2}{*}{ Variables } & \multicolumn{2}{|l|}{ Drug injection } & \multicolumn{2}{|l|}{ Syringe sharing } \\
\hline & Unadjusted OR & Adjusted OR & Unadjusted OR & Adjusted OR \\
\hline Age & $0.99(0.98 \sim 0.99)^{* * *}$ & $0.98(0.97 \sim 0.99)^{* * *}$ & $0.97(0.96 \sim 0.98)^{* * *}$ & $0.97(0.95 \sim 0.98)^{* * *}$ \\
\hline Years of drug use before MMT & $1.03(1.02 \sim 1.04)^{* * *}$ & $1.04(1.03 \sim 1.06)^{* * *}$ & $1.03(1.02 \sim 1.05)^{* * *}$ & $1.03(1.01 \sim 1.05)^{* *}$ \\
\hline \multicolumn{5}{|l|}{ Sex } \\
\hline Male & $1.55(1.35 \sim 1.79)^{* * *}$ & $1.35(1.08 \sim 1.69)^{*}$ & $1.62(1.25 \sim 2.10)^{* * *}$ & $1.27(0.90 \sim 1.79)$ \\
\hline Female & Reference & Reference & Reference & Reference \\
\hline \multicolumn{5}{|l|}{ Employment status } \\
\hline Employed & $0.96(0.89 \sim 1.04)$ & $0.85(0.74 \sim 0.97)^{*}$ & $1.04(0.92 \sim 1.17)$ & $1.02(0.85 \sim 1.23)$ \\
\hline Unemployed & Reference & Reference & Reference & Reference \\
\hline \multicolumn{5}{|l|}{ Education } \\
\hline Senior school or higher & $0.69(0.61 \sim 0.78)^{* * *}$ & $0.71(0.58 \sim 0.88)^{* *}$ & $0.61(0.49 \sim 0.75)^{* * *}$ & $0.81(0.59 \sim 1.12)$ \\
\hline Junior school & $1.00(0.91 \sim 1.11)$ & $0.98(0.83 \sim 1.16)$ & $1.03(0.23 \sim 4.67)^{* * *}$ & $1.19(0.95 \sim 1.49)$ \\
\hline Primary school & Reference & Reference & Reference & Reference \\
\hline \multicolumn{5}{|l|}{ Marriage status } \\
\hline Married & $0.75(0.69 \sim 0.81)^{* * *}$ & $0.81(0.71 \sim 0.93)^{* *}$ & $0.73(0.65 \sim 0.82)^{* * *}$ & $0.91(0.75 \sim 1.10)$ \\
\hline Unmarried & Reference & Reference & Reference & Reference \\
\hline \multicolumn{5}{|l|}{ HIV status } \\
\hline Positive & $2.12(1.80 \sim 2.49)^{* * *}$ & $1.70(1.23 \sim 2.35)^{* *}$ & $5.22(4.44 \sim 6.15)^{* * *}$ & $4.73(3.53 \sim 6.35)^{* * *}$ \\
\hline Negative & Reference & Reference & Reference & Reference \\
\hline \multicolumn{5}{|l|}{ HCV status } \\
\hline Positive & $1.87(1.70 \sim 2.06)^{* * *}$ & $2.58(2.19 \sim 3.04)^{* * *}$ & $1.67(1.40 \sim 1.99)^{* * *}$ & $1.97(1.51 \sim 2.58)^{* * *}$ \\
\hline Negative & Reference & Reference & Reference & Reference \\
\hline MMT mean dosage & $1.00^{\mathrm{a}}\left(1.00^{\mathrm{b}} \sim 1.00^{\mathrm{c}}\right)^{*}$ & $1.00^{\mathrm{d}}\left(0.99 \sim 1.00^{\mathrm{e}}\right)^{* *}$ & $1.00(1.00 \sim 1.00)$ & $1.00(1.00 \sim 1.00)$ \\
\hline Treatment adherence & $0.42(0.36 \sim 0.48)^{* * *}$ & $0.18(0.16 \sim 0.19)^{* * *}$ & $0.34(0.30 \sim 0.38)^{* * *}$ & $0.42(0.36 \sim 0.48)^{* * *}$ \\
\hline Longest duration of abstinence & $0.86(0.85 \sim 0.87)^{* * *}$ & $0.91(0.89 \sim 0.93)^{* * *}$ & $0.86(0.84 \sim 0.88)^{* * *}$ & $0.92(0.89 \sim 0.95)^{* * *}$ \\
\hline \multicolumn{5}{|l|}{ Unprotected sex } \\
\hline Yes & $1.05(0.95 \sim 1.16)$ & $1.13(0.99 \sim 1.29)$ & $1.13(0.96 \sim 1.33)$ & $1.27(1.06 \sim 1.53)^{* * *}$ \\
\hline No & Reference & Reference & Reference & Reference \\
\hline \multicolumn{5}{|l|}{ Multiple sexual partners } \\
\hline Yes & $1.11(0.96 \sim 1.29)$ & $0.91(0.75 \sim 1.12)$ & $1.42(1.15 \sim 1.77)^{* *}$ & $1.49(1.17 \sim 1.90)^{* *}$ \\
\hline No & Reference & Reference & Reference & Reference \\
\hline
\end{tabular}

${ }^{*} P<0.05,{ }^{* *} P<0.01,{ }^{* * *} P<0.001$.

Exact value: ${ }^{\text {a }: 0.998 ;}{ }^{\text {b. }: 0.996 ;}{ }^{c}: 0.999 ;{ }^{d}: 0.995 ;{ }^{\text {e: }} 0.998$

dosage of methadone, lower level of treatment adherence, shorter duration of abstinence and injecting drugs prior to MMT.

The significant predictors for multiple sexual partners included younger age, being unmarried, HIV negative, $\mathrm{HCV}$ positive, lower level of treatment adherence, shorter duration of abstinence and sharing needles prior to MMT.

\section{Discussion}

Our data revealed that MMT client HIV-risk behaviors had decreased over the course of treatment, especially in the first 6 months, indicating positive effects of MMT on
HIV prevention. These findings were consistent with previous studies on the effect of MMT [9,39-41], especially in China [42,43]. We found that HIV-positive clients were 1.70 times more likely to continue to engage in drug injection and 4.73 times more likely to continue to share syringes compared to their counterparts at 12 month follow-up, even after controlling for other factors (Table 4), suggesting that awareness of HIV status and HIV counseling may not be sufficient to reduce drug-related risk behaviors [44-46]. In contrast to their drug-related behaviors, HIV-positive individuals in our study were less likely to continue to have unprotected 
Table 5 Generalized linear mixed models (GLMM) logistic regression results: Predictors of continued sexual risk behaviors

\begin{tabular}{|c|c|c|c|c|}
\hline \multirow[t]{2}{*}{ Variables } & \multicolumn{2}{|l|}{ Unprotected sex } & \multicolumn{2}{|c|}{ Multiple sexual partners } \\
\hline & Unadjusted OR & Adjusted OR & Unadjusted OR & Adjusted OR \\
\hline Age & $1.03(1.03 \sim 1.04)^{* * *}$ & $1.02(1.01 \sim 1.03)^{* * *}$ & $0.97(0.96 \sim 0.98)^{* * *}$ & $0.98\left(0.97 \sim 1.00^{\mathrm{a}}\right)^{*}$ \\
\hline Years of drug use before MMT & $1.02(1.01 \sim 1.03)^{* * *}$ & $1.01\left(1.00^{b} \sim 1.02\right)^{*}$ & $0.99(0.97 \sim 1.00)$ & $0.99(0.98 \sim 1.01)$ \\
\hline \multicolumn{5}{|l|}{ Gender } \\
\hline Male & $1.03(0.86 \sim 1.22)$ & $1.10(0.92 \sim 1.32)$ & $0.80(0.60 \sim 1.08)$ & $0.80(0.59 \sim 1.08)$ \\
\hline Female & Reference & Reference & Reference & Reference \\
\hline \multicolumn{5}{|l|}{ Employment status } \\
\hline Employed & $0.80(0.72 \sim 0.88)^{* * *}$ & $0.82(0.74 \sim 0.91)^{* * *}$ & $1.09(0.93 \sim 1.27)$ & $1.16(0.99 \sim 1.36)$ \\
\hline Unemployed & Reference & Reference & Reference & Reference \\
\hline \multicolumn{5}{|l|}{ Education } \\
\hline Senior school or higher & $1.08(0.92 \sim 1.26)$ & $1.11(0.94 \sim 1.31)$ & $0.94(0.73 \sim 1.22)$ & $0.98(0.75 \sim 1.27)$ \\
\hline Junior school & $0.99(0.87 \sim 1.12)$ & $1.02(0.89 \sim 1.17)$ & $1.16(0.95 \sim 1.42)$ & $1.11(0.90 \sim 1.36)$ \\
\hline Primary school & Reference & Reference & Reference & Reference \\
\hline \multicolumn{5}{|l|}{ Marriage status } \\
\hline Married & $1.43(1.30 \sim 1.58)^{* * *}$ & $1.35(1.21 \sim 1.50)^{* * *}$ & $0.57(0.49 \sim 0.67)^{* * *}$ & $0.58(0.49 \sim 0.69)^{* * *}$ \\
\hline Unmarried & Reference & Reference & Reference & Reference \\
\hline \multicolumn{5}{|l|}{ HIV status } \\
\hline Positive & $0.43(0.34 \sim 0.55)^{* * *}$ & $0.43(0.33 \sim 0.55)^{* * *}$ & $0.61(0.42 \sim 0.89)^{*}$ & $0.49(0.33 \sim 0.74)^{* *}$ \\
\hline Negative & Reference & Reference & Reference & Reference \\
\hline \multicolumn{5}{|l|}{ HCV status } \\
\hline Positive & $0.97(0.85 \sim 1.11)$ & $0.84(0.73 \sim 0.96)^{* * *}$ & $1.48(1.21 \sim 1.83)^{* * *}$ & $1.47(1.18 \sim 1.84)^{* *}$ \\
\hline Negative & Reference & Reference & Reference & Reference \\
\hline MMT mean dosage & $0.99\left(0.99 \sim 1.00^{c}\right)^{* * *}$ & $1.00^{\mathrm{d}}\left(0.99 \sim 1.00^{\mathrm{e}}\right)^{* * *}$ & $1.00(1.00 \sim 1.00)$ & $1.00(1.00 \sim 1.01)$ \\
\hline Treatment adherence & $1.00^{f}\left(0.99 \sim 1.00^{g}\right)^{*}$ & $0.99\left(0.99 \sim 1.00^{h}\right)^{* * *}$ & $0.98(0.97 \sim 0.99)^{* * *}$ & $0.98(0.97 \sim 0.99)^{* * *}$ \\
\hline Longest duration of abstinence & $0.99\left(0.97 \sim 1.00^{i}\right)^{*}$ & $0.96(0.94 \sim 0.98)^{* * *}$ & $0.97(0.95 \sim 0.99)^{* *}$ & $0.97\left(0.95 \sim 1.00^{j}\right)^{*}$ \\
\hline \multicolumn{5}{|l|}{ Drug injection } \\
\hline Yes & $1.12(0.99 \sim 1.27)$ & $0.75(0.65 \sim 0.86)^{* * *}$ & $0.92(0.75 \sim 1.13)$ & $0.93(0.74 \sim 1.15)$ \\
\hline No & Reference & Reference & Reference & Reference \\
\hline \multicolumn{5}{|l|}{ Syringes sharing } \\
\hline Yes & $0.88(0.77 \sim 1.00)$ & $0.97(0.84 \sim 1.12)$ & $0.77(0.63 \sim 0.93)^{* *}$ & $0.77(0.63 \sim 0.95)^{*}$ \\
\hline No & Reference & Reference & Reference & Reference \\
\hline
\end{tabular}

${ }^{*} P<0.05,{ }^{* *} P<0.01,{ }^{* * *} P<0.001$.

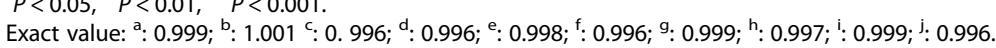

sex and have multiple sexual partners (Table 5). Although HIV-prevention counseling is a part of MMT programs in China, our data underscore the inadequacy or limited effect of drug-related HIV-prevention counseling. Programs to reduce drug-risk behaviors targeting HIVpositive individuals are urgently needed $[40,47,48]$.

$\mathrm{HCV}$-positive clients were 2.58 times more likely to continue to inject drugs, 1.97 times more likely to continue to share syringes (Table 4), and 1.47 times more likely to continue to have multiple sexual partners (Table 5); their drug-related HIV-risk behaviors resembled those in previous studies [49-51]. More than $70 \%$ of IDU in
Guangdong province are infected with $\mathrm{HCV}$ (in our study $78 \%$ were $\mathrm{HCV}$ positive) [52], but $\mathrm{HCV}$ counseling and treatment were not part of the MMT protocol partly because the MMT programs were established in response to the growing HIV/AIDS epidemic. Our data suggest an urgent need to include effective $\mathrm{HCV}$-prevention counseling in MMT.

We note that the most significant factor in reducing HIV risks was treatment adherence; in other words, MMT clients who better adhered to the treatment and stayed in the program longer were more likely to reduce their drug- or sex-related risk behaviors, suggesting that more 
exposure to MMT was effective in reducing HIV risks. Such findings suggest the need for measures to promote adherence among MMT clients. Inconsistent results were reported in previous studies on the relationship between treatment adherence and methadone dosage. Ramli $M$ et al. demonstrated that there was a positive association between these two factors [53], on the contrary, methadone maintenance dose was not associated with improved treatment adherence in Zhao L's study [54]. The current study did not focus on this relationship; however, further studies are clearly required to investigate impact of methadone dose on treatment adherence. Other risk factors included younger age, longer history of drug abuse, being male, unemployment, less education, and being single. These findings provide important information by identifying at-risk individuals who could benefit from targeted interventions to reduce their HIV risk.

The current study has several limitations. First, we had a relatively high attrition rate: $38 \%$ at first follow-up and $61 \%$ at second follow-up. We did not employ any retention efforts during the study as it was a longitudinal observational study rather than an intervention study. Although the rate of dropout is high, this is typical in MMT clinics and highlights the need for future research to increase retention in these programs. The attrition rates observed in the current study were similar to previous MMT studies in China [20-23]. Nevertheless, the data presented in the current study might be biased towards "good clients." We learned that those who dropped out were more likely to be male, younger, unemployed, and HIV positive and have shorter history of drug abuse. Therefore, future studies are needed to target these drug users who were more likely to drop out of MMT and determine reasons for dropping out. Second, we have used self-reported data for all study predictors; thus, recall or social desirability biases might be present. Third, we included only a limited number of outcome and independent variables in the survey; other important psychosocial measures, such as mental health status as well as structural factors such as social support and social networks [55] were not included. These variables might explain more about the relationship between continued HIV-risk behaviors and MMT characteristics. Finally, our study was conducted in selected MMT clinics in Guangdong Province of south China; the data might not be generalizable to other MMT clients living elsewhere in China.

Despite these limitations, our study represents one of the first efforts to use a prospective design to evaluate the factors associated with continued HIV-risk behaviors during the course of MMT. We found that HIV- and HCV-positive status were strongly associated with drug- and sex-related risk behaviors, which underscore the urgency to strengthen HIV counseling, especially drug-risk reduction in the current MMT programs. Given the high prevalence of $\mathrm{HCV}$ in China we adding counseling services for $\mathrm{HCV}$ - positive MMT clients is urgently needed. The high attrition rate and strong association of MMT adherence and HIV-risk reduction suggest the importance of enhancing adherence among MMT clients. MMT has been scaled-up nationwide in China since 2006 [17], and its "revolving-door" effect has been reported in previous studies [10,56,57]. Because the positive effect of MMT and its extensive reach have been confirmed in the past decade $[2,5,6]$, now is a critical time to adjust the program to improve implementation effectiveness. Motivating drug users to adhere to the program longer and reducing HIV risks and drug abuse require greater efforts than the MMT program. They require structural interventions, such as programs to reduce the stigma associated with drug users and HIV-positive individuals as well as a social support system for vulnerable drug users, especially younger, unmarried, and unemployed individuals.

\section{Conclusions}

Our data confirmed the positive effects of MMT on HIV prevention and underscored the urgency for programs to reduce $\mathrm{HIV}$ risk in $\mathrm{HIV}$ - and $\mathrm{HCV}$-positive clients. We call to strengthen the existing counseling services for HIV-positive drug users to reduce their drug-related risk behaviors and to provide counseling for $\mathrm{HCV}$-positive drug users. Future studies are needed to explore interventions to address high dropout rates and low adherence among MMT clients.

\section{Competing interests}

All authors have declared no conflicts of interest.

\section{Authors' contributions}

LL conceptualized the study and wrote the protocol, WC and XY led the data collection and, WC led the data analysis and wrote the first draft of the manuscript. $\mathrm{YH}$ led the manuscript development. $\mathrm{BJH}$ contributed to the writing and preparation of the manuscript revision. All authors have contributed to and approved the final manuscript.

\section{Acknowledgments}

This project is funded by National Natural Science Foundation of China (\#30972552, \#71173245), Guangdong Natural Science Foundation (\#9151008901000023) and China Global Fund AIDS Program Round 6. Dr. Chen and Dr. Hall's contribution to this work also was through the Fogarty Global Health Fellows Program Consortium comprised of the University of North Carolina, John Hopkins Bloomberg School of Public Health, Morehouse and Tulane (\#5R25TW009340, 1R25TW009340-01). The views presented in the paper are the sole responsibilities of the authors and do not represent the official views of the funding agencies.

\section{Author details}

'Faculty of Medical Statistics and Epidemiology, School of Public Health, Sun Yat-sen University, \#74, Zhongshan Road II, Guangzhou 510080, P.R China. ${ }^{2}$ Sun Yat-sen Center for Migrant Health Policy, \#74, Zhongshan Road II, Guangzhou 510080, P.R China. ${ }^{3}$ Department of Social and Behavioral Health School of Rural Public Health Texas A\&M University, TAMU 1266, College Station, TX 77843-1266, USA. ${ }^{4}$ UNC-Project China, Guangdong STD Control 
Center, Guangzhou 510095, P.R China. ${ }^{5}$ Department of Mental Health, Johns Hopkins Bloomberg School of Public Health, Hampton House, 8th Floor, 624 N. Broadway, Baltimore, MD 21205, USA.

Received: 6 January 2013 Accepted: 30 September 2013 Published: 10 October 2013

\section{References}

1. United Nations Office on Drugs and Crime: World drug report 2012. Vienna: United Nations publication, Sales No. E.12.XI.1; 2012.

2. Dole VP, Nyswander M: Methadone maintenance 4 decades later thousands of lives saved but still controversial. JAMA 2008, 300(19):2303-2305.

3. Mattick RP, Breen C, Kimber J, Davoli M: Methadone maintenance therapy versus no opioid replacement therapy for opioid dependence. Cochrane Database Syst Rev 2009, 3, CD002209.

4. Sees KL, Delucchi KL, Masson C, Rosen A, Clark HW, Robillard H, Banys P, Hall SM: Methadone maintenance vs 180-Day psychosocially enriched detoxification for treatment of opioid dependence a randomized controlled trial. JAMA 2000, 283(10):1303-1310.

5. Metzger DS, Woody GE, O'Brien CP: Drug treatment as HIV prevention: a research update. J Acquir Immune Defic Syndr 2010, 55(Suppl 1):32-36.

6. Sorensen JL, Coepland AL: Drug abuse treatment as an HIV prevention strategy: a review. Drug Alcohol Depend 2000, 59(1):17-31.

7. Ball JC, Lange WR, Myers CP, Friedman SR: Reducing the risk of AIDS through methadone maintenance treatment. J Health Soc Behav 1988, 29(2):214-226.

8. Hartel DM, Schoenbaum EE: Methadone treatment protects against HIV infection: two decades of experience in the Bronx, New York City. Public Health Rep 1998, 113(Suppl 1):107-115.

9. Choopanya K, Des Jarlais DC, Vanichseni S, Mock PA, Kitayaporn D, Sangkhum U, Prasithiphol B, Hiranrus K, van Griensven F, Tappero JW, et al: HIV risk reduction in a cohort of injecting drug users in Bangkok, Thailand. J Acquir Immune Defic Syndr 2003, 33(1):88-95.

10. Qian HZ, Hao C, Ruan Y, Cassell HM, Chen K, Qin G, Yin L, Schumacher JE, Liang S, Shao Y: Impact of methadone on drug use and risky sex in China. J Subst Abuse Treat 2008, 34(4):391-397.

11. Department of Health and Human Services: Methadone maintenance treatment. Atlanta: Centers for Disease Control and Prevention; 2002

12. National Narcotic Control Commission: Annual National Narcotic Control Report 2011. Beijing: Ministry of Public Security; 2011.

13. Qian HZ, Schumacher JE, Chen HT, Ruan YH: Injection drug use and HIV/ AIDS in China: review of current situation, prevention and policy implications. Harm Reduction J 2006, 3:4.

14. Standing Office of National People's Congress China: Standing Office of National People's Congress China. Regulations on Prohibition against Narcotics. Beijing: Standing Office of National People's Congress; 1990.

15. Wang L: Overview of the HIV/AIDS epidemic, scientific research and government responses in China. AIDS 2007, 21(Suppl 8):3-7.

16. Ministry of Health China, UNAIDS, WHO: The estimation of HIV/AIDS epidemic in China, 2011. Beijing: National center for AIDS/STD control and prevention, China CDC; 2011.

17. Yin W, Hao Y, Sun X, Gong X, Li F, Li J, Rou K, Sullivan SG, Wang C, Cao X, et al: Scaling up the national methadone maintenance treatment program in China: achievements and challenges. Int J Epidemiol 2010, 39(Suppl 2):29-37.

18. Li J, Ha TH, Zhang C, Liu H: The Chinese government's response to drug use and HIV/AIDS: A review of policies and programs. Harm Reduction J 2010, 5(7):4.

19. Ministry of Health China, Ministry of Security China, State FDA China: National guideline of community-based methadone maintenance treatment to opioid-addicts in China. Bei Jing: Ministry of Health China; 2006.

20. He Q, Wang XR, Xia YH, Mandel JS, Chen A, Zhao LL, Han L, Ling L: New community-based methadone maintenance treatment programs in Guangdong, China, and their impact on patient quality of life. Subst Use Misuse 2011, 46(6):749-757.

21. Gu J, Xu HF, Lau JTF, Hao YT, Zhong Y, Fan LR, Zhao YT, Hao C, Ling WH: Misconceptions predict prospectively dropout and poor adherence among newly admitted first-time methadone maintenance treatment clients in Guangzhou, China. Addiction 2012, 107(9):1641-1649.

22. Chen $A$, Xia YH, Chen W, Ling L, Tan WK, Zheng JR: Predictors of retention related factors at the initial methadone maintenance treatment clinics in Guangdong province. Zhonghua Liu Xing Bing Xue Za Zhi 2009, 30(12):1230-1233.
23. Li XL, Tan HZ, Sun ZQ, Zhang H, Chen MS, Ou QY: Study on the time of retention and related influencing factors of patients receiving methadone maintenance treatment in Hunan province. Zhonghua Liu Xing Bing Xue Za Zhi 2009, 30(7):672-675.

24. Wang ZC, Zhong HJ, Wang L, Huang GY, Li SC, Li JL: Factors and interventions associated with adherence to methadone maintenance treatment. China Prev Med 2008, 9(4):309-312.

25. Zhang YZ, Shan H, Trizzino J, Ruan YH, Beauchamp G, Mâsse B, Jun M, Yuan G, Yixin $\mathrm{H}$, Baoling R, et al: Demographic characteristics and risk behaviors associated with HIV positive injecting drug users in Xinjiang, China. J Infect 2007, 54(3):285-290.

26. Ruan YH, Qin GM, Liu SZ, Qian HZ, Zhang L, Zhou F, He Y, Chen K, Yin L, Chen $X$, et al: HIV incidence and factors contributed to retention in a 12-month follow-up study of injection drug users in Sichuan province, China. J Acquir Immune Defic Syndr 2005, 39(4):459-463.

27. Lee TS, Shen HC, Wu WH, Huang CW, Yen MY, Wang BE, Chuang P, Shih CY, Chou YC, Liu YL: Clinical characteristics and risk behavior as a function of HIV status among heroin users enrolled in methadone treatment in northern Taiwan. Subst Abuse Treat Prev Policy 2011, 8(6):6.

28. Avants SK, Warburton LA, Hawkins KA, Margolin A: Continuation of high -risk behavior by HIV-positive drug users treatment implication. J Subst Abuse Treat 2000, 19(1):15-22.

29. Corsi KF, Lehman WK, Booth RE: The effect of methadone maintenance on positive outcomes for opiate injection drug users. I Subst Abuse Treat 2009, 37(2):120-126.

30. Li H, Goggins W, Lee SS: Multilevel analysis of HIV related risk behaviors among heroin users in a low prevalence community. BMC Public Health 2009, 12(9):137.

31. He X: The number of HIV infected individuals in Guangdong Province has been reduced 16000 within the last 16 years. In Guangzhou Daily. Guangzhou: Guangzhou Daily Press; 2012:11-29.

32. Li NN: Sixty and thirty percentages of new HIV infections in Guangdong last year because of sexually and drug injected transmisiion, respectively. Guangzhou: Information times; 2011.

33. Department of Health of Guangdong Province: Report on HIV/AIDS prevention and control of Guangdong province, 2011. Guangzhou: Department of Health; 2011.

34. World Health Organization: International Statistical Classification of Diseases and Related Health Problems 10th Revision (ICD-10) Version for 2010. http:// apps.who.int/classifications/icd10/browse/2010/en.

35. Liu EW, Liang T, Shen LM, Zhong H, Wang B, Wu ZY, Detels R: Impact of methadone maintenance treatment on HIV risk behaviors of heroin drug users. Zhonghua Yu Fang Yi Xue Za Zhi 2010, 44(11):981-984.

36. Zhao L, Holzemer WL, Johnson M, Tulsky JP, Rose CD: HIV infection as a predictor of methadone maintenance outcomes in Chinese injection drug users. AIDS Care 2012, 24(2):195-203.

37. Peirce JM, Petry NM, Stitzer ML, Blaine J, Kellogg S, Satterfield F, Schwartz M, Krasnansky J, Pencer E, Silva-Vazquez L, et al: Effects of lower-cost incentives on stimulant abstinence in methadone maintenance treatment: a national drug abuse treatment clinical trials network study. Arch Gen Psychiatry 2006, 63(2):201-208.

38. Akaike H: A new look at the statistical model identification. IEEE Trans Automat Contr 1974, 19(6):716-723.

39. Millson P, Challacombe L, Villeneuve PJ, Strike CJ, Fischer B, Myers T, Shore R, Hopkins S: Reduction in injection-related HIV risk after 6 months in a low-threshold methadone treatment program. AIDS Educ Prev 2007, 19(2):124-136

40. Strathdee SA, Patterson TL: Behavioral interventions for HIV-positive and HCV-positive drug users. AIDS Behav 2006, 10(2):115-130.

41. Murphy DA, Brecht ML, Herbeck D, Evans E, Huang D, Hser YI: Longitudinal HIV risk behavior among the Drug Abuse Treatment Outcome Studies (DATOS) adult sample. Eval Rev 2008, 32(1):83-112.

42. Guo YL, Zhou JB, Hao C, Shi TP, Li JH, Chen SL: The effectiveness of community-based methodone maintenance treatment on the change of high-risk behavior among heroin addicts. Chinese J Drug Abuse Prev Treat 2010, 16(5):253-255.

43. Zhao YT, Xu HF, Fan LR: Evaluation for the community-based methadone maintenance treatment in Guangzhou City. J Trop Med 2009, 9(9):229-331.

44. van den Hoek JA, van Haastrecht HJ, Coutinho RA: Risk reduction among intravenous drug users in Amsterdam under the influence of AIDS. Am J Public Health 1989, 79(10):1355-1357. 
45. Calsyn DA, Saxon AJ, Freeman G, Whittaker S: Ineffectiveness of AIDS education and HIV antibody testing in reducing high-risk behaviors among injection drug users. Am J Public Health 1992, 82(4):573-575.

46. Farley TA, Cartter ML, Wassell JT, Hadler JL: Predictors of outcome in methadone programs: effect of HIV counseling and testing. AIDS 1992, 6(1):115-121.

47. Janssen RS, Holtgrave DR, Valdiserri RO, Shepherd M, Gayle HD, De Cock KM: The Serostatus Approach to Fighting the HIV Epidemic: prevention strategies for infected individuals. Am J Public Health 2001, 91(7):1019-1024.

48. Weinhardt LS, Carey MP, Johnson BT, Bickham NL: Effects of HIV counseling and testing on sexual risk behavior: a meta-analytic review of published research, 1985-1997. Am J Public Health 1999, 89(9):1397-1405.

49. Ompad DC, Fuller CM, Vlahov D, Thomas D, Strathdee SA: Lack of behavior change after disclosure of hepatitis $C$ virus infection among young injection drug users in baltimore, Maryland. Clin Infect Dis 2002. 35(7):783-788

50. Vidal-Trécan G, Coste J, Varescon-Pousson I, Christoforov B, Boissonnas A: HCV status knowledge and risk behaviours amongst intravenous drug users. Eur J Epidemiol 2000, 16(5):439-445.

51. Hagan H, Campbell J, Thiede H, Strathdee S, Ouellet L, Kapadia F, Hudson S, Garfein RS: Self-reported hepatitis C virus antibody status and risk behavior in young injectors. Public Health Rep 2006, 121(6):710-719.

52. Wu J, Huang J, Xu D, Lu C, Deng X, Zhou X: Infection status and risk factors of HIV, HBV, HCV, and syphilis among drug users in Guangdong, China-a cross-sectional study. BMC Public Health 2010, 1(10):657.

53. Ramli M, Zafri AB, Junid MR, Hatta S: Associated risk factors to non-compliance to methadone maintenance therapy. Med J Malaysia 2012, 67(6):560-564.

54. Zhao L, Holzemer WL, Tulsky JP, Johnson MO, Dawson RC: Effect of methadone dose on maintenance treatment and health consequences among heroin addicts in South China. Subst Use Misuse 2013. in press.

55. Latkin CA, Davey-Rothwell MA, Knowlton AR, Alexander KA, Williams CT, Boodram B: Social network approaches to recruitment, HIV prevention, medical care, and medication adherence. J Acquir Immune Defic Syndr 2013, 63(Suppl 1):54-58.

56. Pang L, Hao Y, Mi G, Wang C, Luo W, Rou K, Li J, Wu ZY: Effectiveness of first eight methadone maintenance treatment clinics in China. AIDS 2007, 21(Suppl 8):103-107.

57. Shi J, Zhao LY, Epstein DH, Zhao C, Shuai Y, Yan B, Jin J, Lu L: The effect of methadone maintenance on illicit opioid use, human immunodeficiency virus and hepatitis C virus infection, health status, employment, and criminal activity among heroin abusers during 6 months of treatment in china. J Addict Med 2007, 1(4):186-190.

doi:10.1186/1477-7517-10-23

Cite this article as: Chen et al:: Predictors of continued HIV-risk behaviors among drug users in methadone maintenance therapy program in China-A prospective study. Harm Reduction Journal 2013 10:23.

\section{Submit your next manuscript to BioMed Central and take full advantage of:}

- Convenient online submission

- Thorough peer review

- No space constraints or color figure charges

- Immediate publication on acceptance

- Inclusion in PubMed, CAS, Scopus and Google Scholar

- Research which is freely available for redistribution 